\title{
Steady State Analytical Study of Stator Current Harmonic Spectrum Components on Three-Phase Induction Motor under Unbalanced Supply Voltage
}

\author{
Fatima BABAA \\ Electrical Laboratory of Constantine "LEC", \\ University Constantine 1 \\ 25000 Constantine, ALGERIA \\ babaa.fatima@yahoo.fr
}

\author{
Ouafae. BENNIS \\ Prisme Laboratory, \\ University of Orleans, \\ 28000 Chartres, FRANCE
}

\begin{abstract}
Almost all induction motor applications suffer from unbalanced supply voltage. Under such conditions the motor operation can be seriously affected. Performance, control and monitoring are directly connected to the knowledge of the supply harmonics effects on the motor, therefore there is a real need to derive a general mathematical formula predicting the harmonics growth and to describe through an analytical analysis in steady state operation, the impact of unbalanced voltage supply on induction machine performance. In this paper an original analytical formula of harmonics components is developed to propose an accurate indicator of unbalanced supply voltage fault. The validity of this analytical study is confirmed by a comparison with simulation and experimental results.
\end{abstract}

Keywords- Unbalanced supply voltage, Harmonics components, Sensitive indicator, Induction motor, Analytical study

\section{NOMENCLATURE}

\begin{tabular}{|c|c|}
\hline$\omega$ & fundamental pulsation \\
\hline$f$ & frequency of the supply voltage $(50 \mathrm{HZ})$ \\
\hline$V_{s d}$ & $\begin{array}{l}\text { effective values of the supply voltages } \\
\text { of the direct systems }\end{array}$ \\
\hline$V_{s i}$ & $\begin{array}{l}\text { effective values of the supply voltages } \\
\text { of inverse systems }\end{array}$ \\
\hline & stator time constant \\
\hline & rotor time constant \\
\hline$\sigma=1-M^{2} /$ & leakage factor \\
\hline$i_{s a}$ & Stator current \\
\hline $\mathfrak{R e}()$ & Real part of the quantity \\
\hline$\Gamma_{e d}$ & Direct electromagnetic torque \\
\hline$\Gamma_{e i}$ & Inverse electromagnetic torque \\
\hline$\Delta \Gamma$ & pulsating electromagnetic torques. \\
\hline
\end{tabular}

\section{INTRODUCTION}

Cage induction motor is the most electromechanical form used in many areas such as electromechanical drive for industrial, commercial and domestic applications. Diagnosing failures of industrial systems, if it can be possible to identify in a timely manner, represents one of the means of increasing gain points of productivity. Research investigations have concentrated to provide an indication of the healthiness of the machine [1....5]. In practice, machine operations cannot be under perfectly balanced supply voltage conditions.

The most important effect of an unbalanced supply voltage is the creation of a reverse current. This component produces a negative electromagnetic force that gives variations of some harmonic components of the stator current. These harmonic components interact with the main magnetic field and provoke an oscillation torque and speed with a frequency of $2 f_{s}$ [6....9]. When a fault occurs in induction machine such as stator, rotor or bearing faults, they cause unbalanced air-gap magnetomotive force, which leads to other unbalanced phase voltages and line currents. These anomalies produce a variety of components and the detection of faults becomes.Indeed, most complicated factors for analyzing these spectrums are the small unbalance in the supply voltage and/or in the machine structure that exists in any real system. Under such conditions, many current components are reported to be effective indicators for the unbalanced supply voltage. The first component $-f_{s}$ is the direct consequence of this anomaly and the second one $3 f_{s}$ is due to speed ripples [7], [8]. However, the rise in these components also results from any machine asymmetries like inter-turn short-circuit fault. Therefore, the investigation of the performance degradation of induction machine under unbalanced supply voltage conditions is of considerable importance to distinguish between anomaly in the machine and any voltage distortion. The main aim of this paper is to give an accurate formula of the harmonics components in the stator current to extract a good indicator of the unbalanced supply voltage and to understand how harmonics grow up due to the imbalance. We confirm the validity of the analytical development by a comparison with simulation and experimental results.

\section{Steady State ANAlysis Of ThreE-Phase INDUCtion MACHINE UNDER UNBALANCED VOLTAGE SUPPLY}

The most important effect of an unbalanced supply voltage is the creation of a reverse current. This component produces a negative electromagnetic force that gives 
variations of certain harmonic components of the stator current. These harmonic components interact with the main magnetic field and provoke an oscillation torque and speed with a frequency of $2 f_{s}$.

The three-phase unbalanced voltages are represented the following positive and negative sequences phasors:

$$
\left\{\begin{array}{l}
v_{S a}=V_{s d} \sqrt{2} \cos (\omega t)+V_{s i} \sqrt{2} \cos (\omega t) \\
v_{S b}=V_{s d} \sqrt{2} \cos \left(\omega t-\frac{2 \pi}{3}\right)+V_{s i} \sqrt{2} \cos \left(\omega t+\frac{2 \pi}{3}\right) \\
v_{S b}=V_{s d} \sqrt{2} \cos \left(\omega t+\frac{2 \pi}{3}\right)+V_{s i} \sqrt{2} \cos \left(\omega t-\frac{2 \pi}{3}\right)
\end{array}\right.
$$

We use the KU transform to develop the analytical formula because of more significant simplification than other transformations. The transformation of three-phase to twophase quantities by mean of KU transformation is given by:

$V_{s f}=\sqrt{\frac{3}{2}}\left(V_{s d} e^{+i \omega t}+V_{s i} e^{-i \omega t}\right)$

In steady state, the time differential operator $d / d t$ can be replaced by $j \omega$. We have:

$$
\left\{\begin{array}{l}
V_{s f}=R_{s} i_{s f}+L_{s} \frac{d i_{s f}}{d t}+M \frac{d i_{r f}}{d t} \\
0=R_{r} i_{r f}+L_{r} \frac{d i_{r f}}{d t}+M \frac{d i_{s f}}{d t}-j \omega_{r}\left(L_{r} i_{r f}+M i_{s f}\right)
\end{array}\right.
$$

The response of the machine to the positive and negative sequence voltage supply can be represented by:

$$
\begin{aligned}
& i_{s f d}=\sqrt{\frac{3}{2}} V_{s d} e^{j \omega t}\left(\begin{array}{l}
1+\tau_{r}^{2}\left(\omega-\omega_{r}\right)^{2}+ \\
\frac{+\tau_{s} \tau_{r}(1-\sigma) \omega\left(\omega-\omega_{r}\right)}{R_{s} \operatorname{det} A_{1}}
\end{array}\right. \\
& \left.\frac{-j\left(\begin{array}{l}
\tau_{s} \omega+ \\
+\sigma \tau_{s} \tau_{r}^{2} \omega\left(\omega-\omega_{r}\right)^{2}
\end{array}\right)}{R_{s} \operatorname{det} A_{1}}\right) \\
& i_{r f d}=\sqrt{\frac{3}{2}} V_{s d} e^{j \omega t} M\left(\omega-\omega_{r}\right) \times \\
& \times\left(\frac{\left(\tau_{s} \omega+\tau_{r}\left(\omega-\omega_{r}\right)\right)+j\left(1-\sigma \tau_{s} \tau_{r} \omega\left(\omega-\omega_{r}\right)\right)}{R_{s} R_{r} \operatorname{det} A_{1}}\right)
\end{aligned}
$$

$$
\begin{array}{r}
i_{s f i}=\sqrt{\frac{3}{2}} V_{s i} e^{-j \omega t}\left(\begin{array}{l}
\left(\begin{array}{l}
1+\tau_{r}^{2}\left(\omega+\omega_{r}\right)^{2}+ \\
+\tau_{s} \tau_{r}(1-\sigma) \omega\left(\omega+\omega_{r}\right)
\end{array}\right) \\
R_{s} \operatorname{det} A_{2}
\end{array}\right. \\
\left.\frac{+j\left(\tau_{s} \omega+\sigma \tau_{s} \tau_{r}^{2} \omega\left(\omega+\omega_{r}\right)^{2}\right)}{R_{s} \operatorname{det} A_{2}}\right)
\end{array}
$$

with :

$$
\begin{aligned}
& i_{s f}=i_{s f d}+i_{s f i} \\
& i_{r f}=i_{r f d}+i_{r f i} \\
& \operatorname{det} \mathrm{A}_{1}=\left(\tau_{\mathrm{s}} \tau_{\mathrm{r}} \sigma\left(\omega-\omega_{\mathrm{r}}\right) \omega-1\right)^{2}+\left(\tau_{r}\left(\omega-\omega_{\mathrm{r}}\right)+\omega \tau_{s}\right)^{2} \\
& \operatorname{det} \mathrm{A}_{2}=\left(\tau_{\mathrm{s}} \tau_{\mathrm{r}} \sigma\left(\omega+\omega_{\mathrm{r}}\right) \omega+1\right)^{2}+\left(\tau_{r}\left(\omega+\omega_{\mathrm{r}}\right)+\omega \tau_{s}\right)^{2}
\end{aligned}
$$

The stator current $i_{s a}$ can be expressed as:

$$
i_{s a}=\frac{2}{\sqrt{3}} \times \mathfrak{R} e\left(i_{s f} e^{j \theta}\right)
$$

The electromagnetic torque is considered as the variation of co-energy produced by a small change in rotor position when the currents are held constant.

$$
\Gamma_{e}=\left[\frac{\partial W_{c o}}{\partial \theta_{m e c}}\right]_{\left(i_{3 s}, i_{r n} \text { const }\right)}
$$

The co-energy is given by:

$$
W_{c o}=\frac{1}{2}\left[\left[i_{3 s}\right]^{t}\left[i_{r n}\right]^{t}\right] \cdot\left[\begin{array}{cc}
{\left[L_{s}\right]} & {\left[M_{s r}\right]} \\
{\left[M_{r s}\right]} & {\left[L_{r}\right]}
\end{array}\right] \cdot\left[\begin{array}{l}
{\left[i_{3 s}\right]} \\
{\left[i_{r n}\right]}
\end{array}\right]
$$

After calculation we obtain:

$$
\Gamma_{e}=2 p \cdot M \cdot j\left(\left(i_{s f d}+i_{s f i}\right)\left(i_{r f d}+i_{r f i}\right)^{*}\right)
$$

where $j^{2}=-1$

The total torque ripple will be:

$$
\Gamma_{e}=\Gamma_{e d}+\Gamma_{e i}+\Delta \Gamma_{e}
$$

After substitution and development we get:

$$
\begin{aligned}
& \Gamma_{e d}=3 V_{s}^{2} M^{2}\left(\omega-\omega_{r}\right) \frac{C_{C}-T_{c d 1} \omega_{r}+T_{c d 2} \omega_{r}^{2}}{R_{s}^{2} R_{r}\left(\operatorname{det} A_{1}\right)^{2}} \\
& \Gamma_{e i}=-3 V_{s i}^{2} M^{2}\left(\omega+\omega_{r}\right) \frac{C_{C}+T_{c d 1} \omega_{r}+T_{c d 2} \omega_{r}^{2}}{R_{s}^{2} R_{r}\left(\operatorname{det} A_{2}\right)^{2}}
\end{aligned}
$$




$$
\Delta \Gamma_{e}(t)=6 V_{s d} V_{s i} M^{2} \omega_{r}\left(\begin{array}{l}
\left(\begin{array}{l}
\left(C_{2}+\omega T_{C 12}\right)+ \\
+\left(-\omega T_{C 32}+T_{C 22}\right) \omega_{r}^{2}
\end{array}\right) \cos (2 \omega t) \\
+\left(\begin{array}{l}
\left(C_{1}-\omega T_{C 11}\right)+ \\
+\left(T_{C 21}-\omega T_{C 31}\right) \omega_{r}^{2}
\end{array}\right) \sin (2 \omega t) \\
R_{s}^{2} R_{r} \cdot \operatorname{det} A_{1} \cdot \operatorname{det} A_{2}
\end{array}\right)
$$

Equation (19) can also be expressed in the following form:

$$
\Delta \Gamma_{e}(t)=\Delta \Gamma_{e} \sin \left(2 \omega t+\varphi_{C}\right)
$$

where:

$$
\Delta \Gamma_{e}=6 V_{s d} V_{s i} M^{2} \omega_{r}\left(\frac{\sqrt{\left(\begin{array}{l}
\left.\left(C_{2}+\omega T_{C 12}\right)+\left(-\omega T_{C 32}+T_{C 22}\right) \omega_{r}^{3}\right)^{2} \\
+\left(\left(C_{1}-\omega T_{C 11}\right)+\left(T_{C 21}-\omega T_{C 31}\right) \omega_{r}^{3}\right)^{2}
\end{array}\right.}}{R_{s}^{2} R_{r} \cdot \operatorname{det} A_{1} \cdot \operatorname{det} A_{2}}\right)
$$$$
\operatorname{tg}\left(\varphi_{C}\right)=\frac{\left(C_{2}+\omega T_{C 12}\right)+\left(-\omega T_{C 32}+T_{C 22}\right) \omega_{r}^{2}}{\left(C_{1}-\omega T_{C 11}\right)+\left(T_{C 21}-\omega T_{C 31}\right) \omega_{r}^{2}}
$$

The constants are given by:

$$
\begin{aligned}
& C_{1}=\left(\begin{array}{l}
\left(2 \tau_{s}+\tau_{r}\right) \omega+\tau_{r}\left(\left(\tau_{r}+\tau_{s}\right)^{2}-2 \sigma \tau_{s}^{2}\right) \omega^{3} \\
-\sigma_{s}^{2} \tau_{r}^{3} \omega^{5}
\end{array}\right) \\
& C_{2}=1+\left(\tau_{r}^{2}-\tau_{s}^{2}-2 \sigma \tau_{s} \tau_{r}\right) \omega^{2}-\sigma \tau_{r}^{2} \tau_{s}\left(\tau_{s}(2-\sigma)+2 \tau_{r}\right) \omega^{4} \\
& T_{C 11}=-\tau_{r}+\left(\tau_{r}\left(\left(\tau_{s}+\tau_{r}\right)^{2}+2 \sigma \tau_{s} \tau_{r}\right)-\sigma^{2} \tau_{s}^{2} \tau_{r}^{3} \omega^{2}\right) \omega^{2} \\
& T_{C 21}=\left(\left(2 \sigma \tau_{s}-\tau_{r}\right)+\sigma^{2} \tau_{s}^{2} \tau_{r} \omega^{2}\right) \tau_{r}^{2} \omega \\
& T_{C 31}=-\tau_{r}^{3}+\sigma^{2} \tau_{s}^{2} \tau_{r}^{3} \omega^{2} \\
& T_{C 12}=2 \tau_{r} \omega\left(\sigma \tau_{r}^{2} \tau_{s} \omega^{2}+\sigma \tau_{s}^{2} \tau_{r} \omega^{2}-\tau_{s}-\tau_{r}\right) \\
& T_{C 22}=\tau_{r}^{2}+\tau_{s} \tau_{r}^{2} \sigma \omega^{2}\left(2 \tau_{r}-\sigma \tau_{s}\right) \\
& T_{C 32}=2 \sigma \tau_{s} \tau_{r}^{3} \omega
\end{aligned}
$$

Unbalanced supply voltage give rise to torque ripples of $2 \mathrm{f}$ which produces also a speed oscillation $\Delta \omega_{r}(t)$ according to the following relationship:

$$
J \frac{d}{d t} \Delta \omega_{r}(t)=\Delta \Gamma_{e}(t)
$$

Finally, the speed oscillation is:

$$
\begin{aligned}
& \Delta \omega_{r}(t)=-\frac{\Delta \Gamma_{e}}{J 2 \omega} \cos (2 \omega t+\varphi) \\
& \Delta \omega_{r}(t)=\frac{\omega_{r 1}}{2}\left(e^{j 2 \omega t}+e^{-j 2 \omega t}\right)
\end{aligned}
$$

Remark: for a machine with no supply asymmetry, the inverse components are nil. Hence, it is possible to consider the symmetrical conditions of the machine by taking into account only the positive forward components.

\section{TheORETICAL DEVElopMent OF ThE HARMONICS COMPONENTS AS CONSEQUENCE OF UNBALANCED SUPPLY VOLTAGE}

An unbalanced supply voltage cause a speed ripples as shows the following relationship [15]:

$\omega_{r}(t)=\omega_{r 0}+\Delta \omega_{r}(t)$

where

$\Delta \omega_{r}(t)=\omega_{r 1} \cos (2 \omega t+\varphi)$

By replacing the quantity of speed ripples in the equation system we get:

$$
\left\{\begin{array}{l}
v_{s f}=R_{s} i_{s f}+L_{s} \frac{d i_{s f}}{d t}+M \frac{d i_{r f}}{d t} \\
0=\left(\begin{array}{l}
R_{r} i_{r f}+L_{r} \frac{d i_{r f}}{d t}+M \frac{d i_{s f}}{d t} \\
-j\left(\omega_{r 0}+\frac{\omega_{r 1}}{2}\left(e^{j 2 \omega t}+e^{-j 2 \omega t}\right)\right)\left(L_{r} i_{r f}+M i_{s f}\right)
\end{array}\right)
\end{array}\right.
$$

After development and application of the superposition principle on the different frequencies, we get the equations which give the direct components of motor currents:

$$
\left\{\begin{array}{l}
0=R_{s} i_{s f 3}+L_{s} \frac{d i_{s f 3}}{d t}+M \frac{d i_{r f 3}}{d t} \\
v_{r f 3}=j \frac{\omega_{r 1}}{2}\left(L_{r} \cdot c s t_{2}+M \cdot c s t_{1}\right) e^{j 3 \omega t} \\
=R_{r} i_{r f 3}+L_{r} \frac{d i_{r f 3}}{d t}+M \frac{d i_{s f 3}}{d t}-j \omega_{r 3}\left(L_{r} i_{r f 3}+M i_{s f 3}\right)
\end{array}\right.
$$

Using the complex notation and after development we get:

$$
i_{s f 3}=\left(\begin{array}{l}
\left(j \frac{3}{2} \omega_{r 1}\left(\begin{array}{l}
L_{r} \cdot c s t_{2} \\
+M \cdot c s t_{1}
\end{array}\right) \omega M_{s r}\right) \times \\
\times\left(\begin{array}{c}
\tau_{r}\left(\omega_{r}-3 \omega\right) \\
-3 \omega \tau_{s} j\left(\left(3 \tau_{s} \tau_{r} \sigma\left(3 \omega-\omega_{r}\right) \times \omega\right)-1\right)
\end{array}\right) \\
R_{s} R_{r} \cdot \operatorname{det} A_{3}
\end{array}\right) e^{j 3 \omega t}
$$

where

$$
\operatorname{det} A_{3}=\left(\left(3 \tau_{s} \tau_{r} \sigma\left(3 \omega-\omega_{r}\right) \omega-1\right)^{2}+\left(\tau_{r}\left(3 \omega-\omega_{r}\right) \omega \tau_{s}\right)^{2}\right)
$$

In the general formulation we have for the positive components and negative components: 


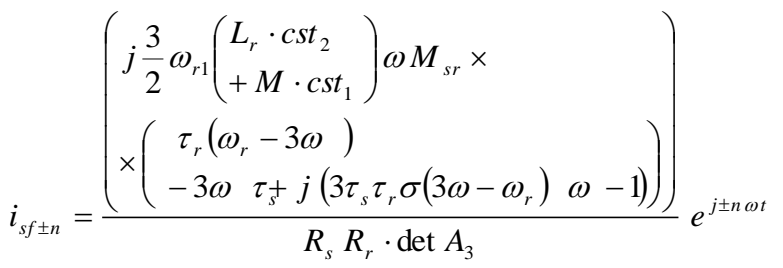

With $\pm n$ is the range of the positive and negative harmonic components.

From the analytical study we can deduce that unbalance in a three phase voltage supply causes negative sequence currents (backward field) in the stator winding. This current interacts with the fundamental frequency rotor currents and produces a pulsating at double main frequency. This pulsating torque produces a speed ripple. The Consequences of this rotor speed variation are the rise or emergence of other frequencies in the stator winding: $3 f_{s}, 5 f_{s}, \ldots \ldots \ldots,(2 \eta+1) f_{s}$ (positive sequence currents) and $-3 f_{s},-5 f_{s}, \ldots \ldots \ldots,-(2 \eta+1) f_{s} \quad$ (negative sequence currents) with $\eta=1,2,3 \ldots \ldots$.

\section{Simulation ReSUlts AND EXPERIMENTAL VALIDATION}

To validate the preceding theoretical results, simulations and experiments were performed. The test motor used in the experimental is a three-phase, $50 \mathrm{~Hz}, 4$-pole, $3 \mathrm{~kW}$, squirrel cage induction motor, type Y100LA, rated at $380 \mathrm{~V}$. Current spectra analysis permits to filter the harmonic components and to give a large amount of spectral information. We insert a series of resistors in one of the phases supplying and we testing the motor under different loads. We applied different unbalanced such as $40 \%$, and $50 \%$ in the voltage amplitude of the concerned phase. For the calculation of the voltage unbalance factor (VUF), we use the expression of the International Electrotechnical Commission $[6,7,9]$.

$(V U F)$ voltage unbalance factor (in $\%)=\frac{V_{n}}{V_{p}}=100 \%$
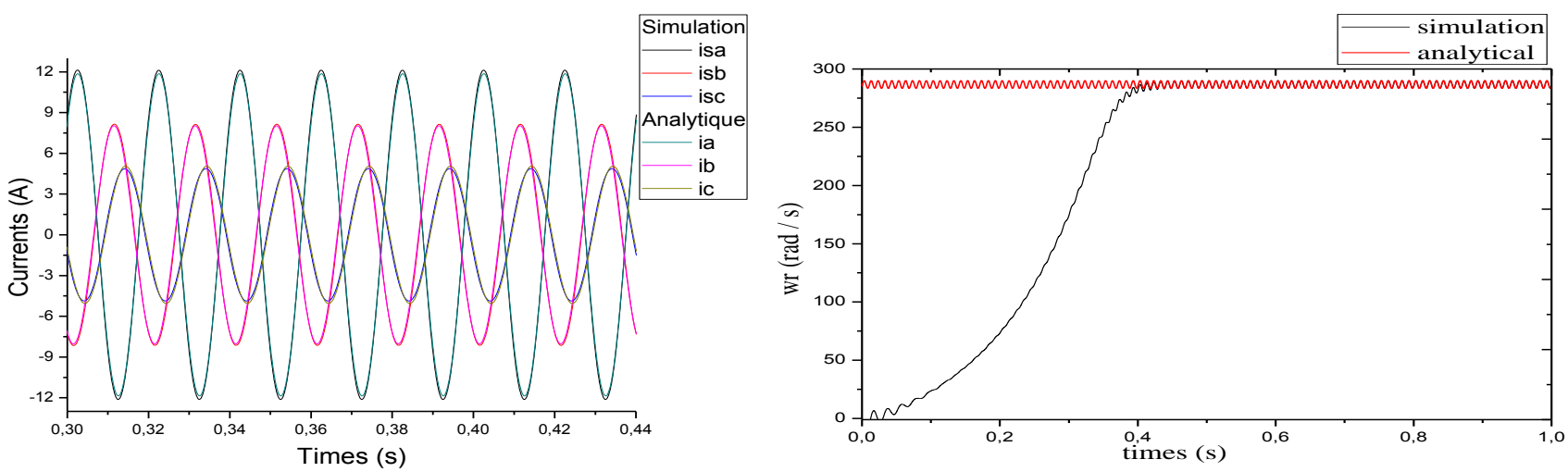

Figure 1. Stator currents and speed of healthy machine under $40 \%$ unbalanced voltage supply on the concerned phase (simulation and analytical).
Where $V p$ and $V n$ are the amplitudes of the positive and negative sequence voltages, respectively. For example, for $40 \%$, and $50 \%$ of unbalance supply, one obtains a VUF $13 \%$, and $17 \%$, respectively.

To obtain stator current simulation, the instantaneous power theory is used [16]. The instantaneous power permit to extract a continuous term which corresponds to negative and positive harmonics components [15].

Waveform of stator current and speed under $40 \%$ unbalanced supply in concerned phasis is represented in Figure 1. We show a total concordance between the analytical study and simulation results. That proves the efficiency of the mathematical development. Figure 2 presents a comparison between simulation and analytical development of the voltage and third negative pulsating current of healthy machine under $40 \%$ of unbalanced supply voltage. We have a total concordance between the analytical results and the simulation ones. This figure shows that the analytical developments of harmonics components are accurate.

Figure 3 represent analytical variation of the negative, the third positive and the third negative sequences harmonics according to the load percentage under different condition of unbalance supply voltage. Figure 4 represents analytical variation of the fifth positive and the fifth negative sequences harmonics according to the load percentage under different conditions of unbalance supply voltage.

Figure 5 and 6 represent variation of the same amplitudes but experimentally. We see in analytical results that variation of harmonics have the same comportment like those found in the experimental. It can be observed on one hand that under unbalanced supply voltage, the amplitude of the direct third harmonic component $(+3 f s)$ and negatives components $(-f s)$ increases significantly with the percentage of the unbalance. We thus find same indexes of imbalance supply as seen in the literature.Indeed, we can confirm that our analytical development is very appreciable.One can notice that the harmonics $(-3 f s)$ and $(-5 f s)$ in stator current are not affected by the unbalanced. 

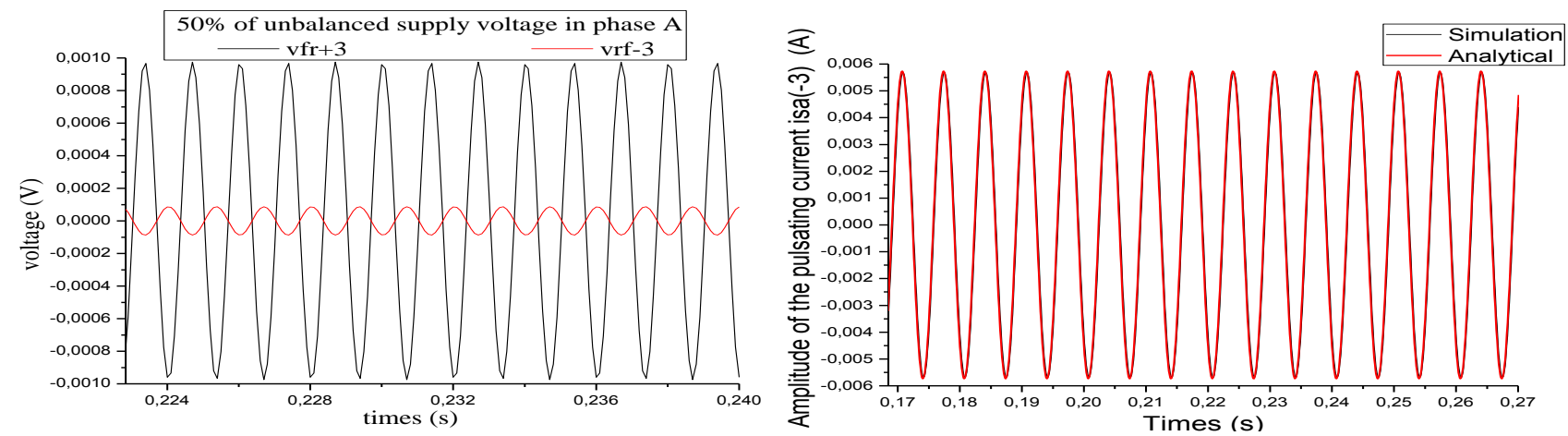

Figure 2. Result of Induced pulsation voltage $3 \mathrm{fs}$ direct and inverse (left) and third negative pulsating current (right) in healthy machine under 50\% unbalanced supply voltage on the concerned phase. (Simulation: solid line, Analytical: dashed line)
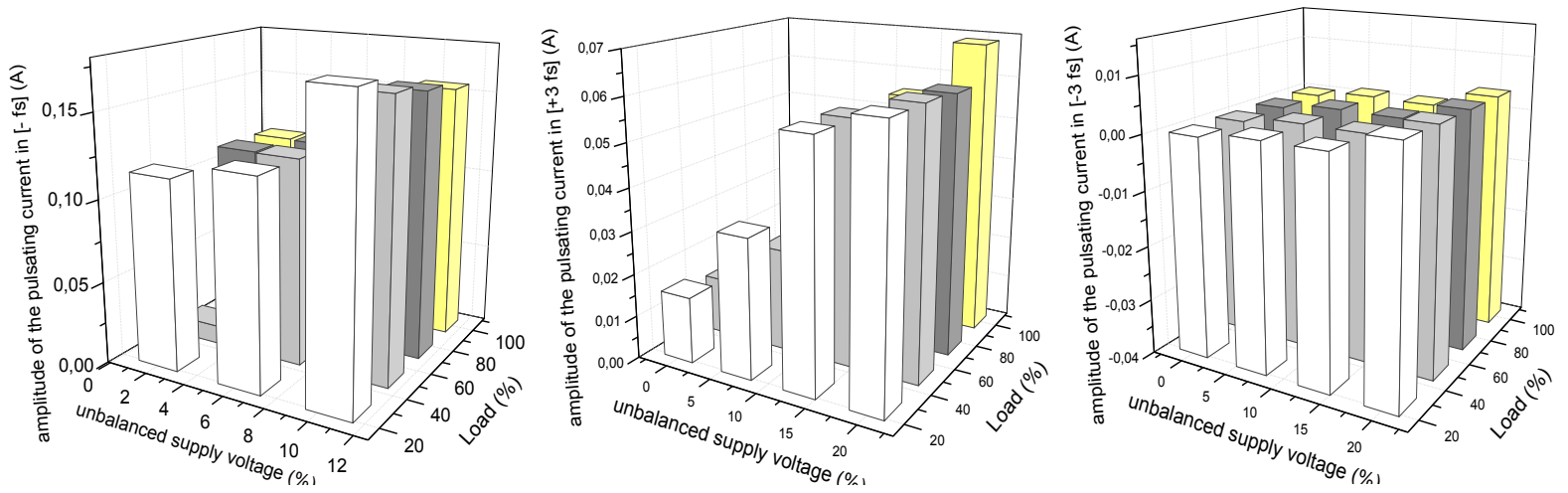

Figure 3. Analytical variation of the negative (left), the third positive (middle) and the third negative (right) sequences harmonics according to the load percentage under different condition of unbalance supply voltage.
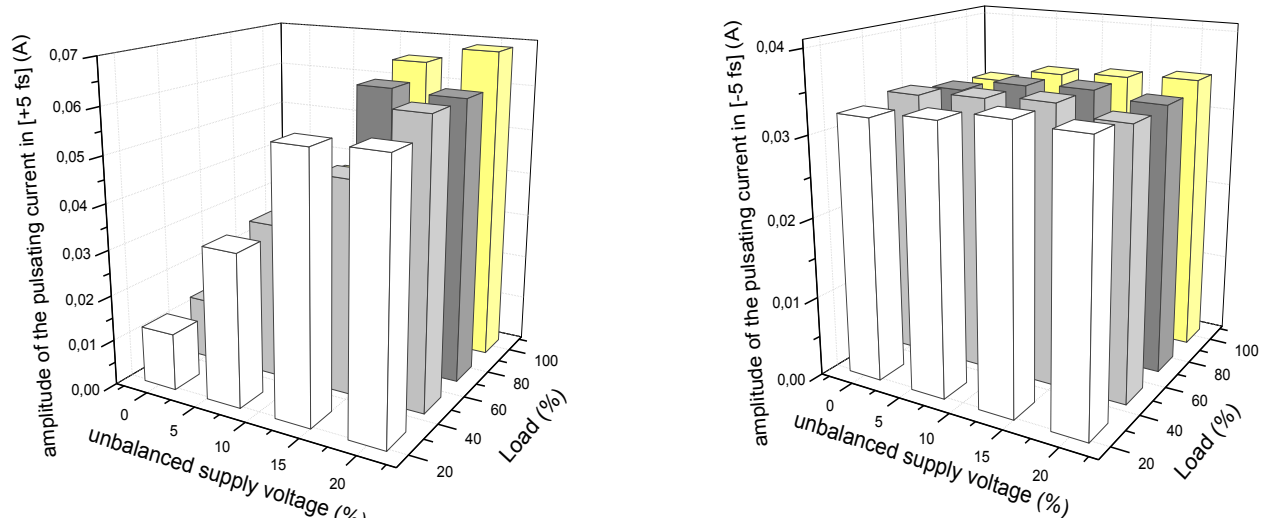

Figure 4. Analytical variation of the fifth positive (left) and the fifth negative (right) sequences harmonics according to the load percentage under different condition of unbalance supply voltage.
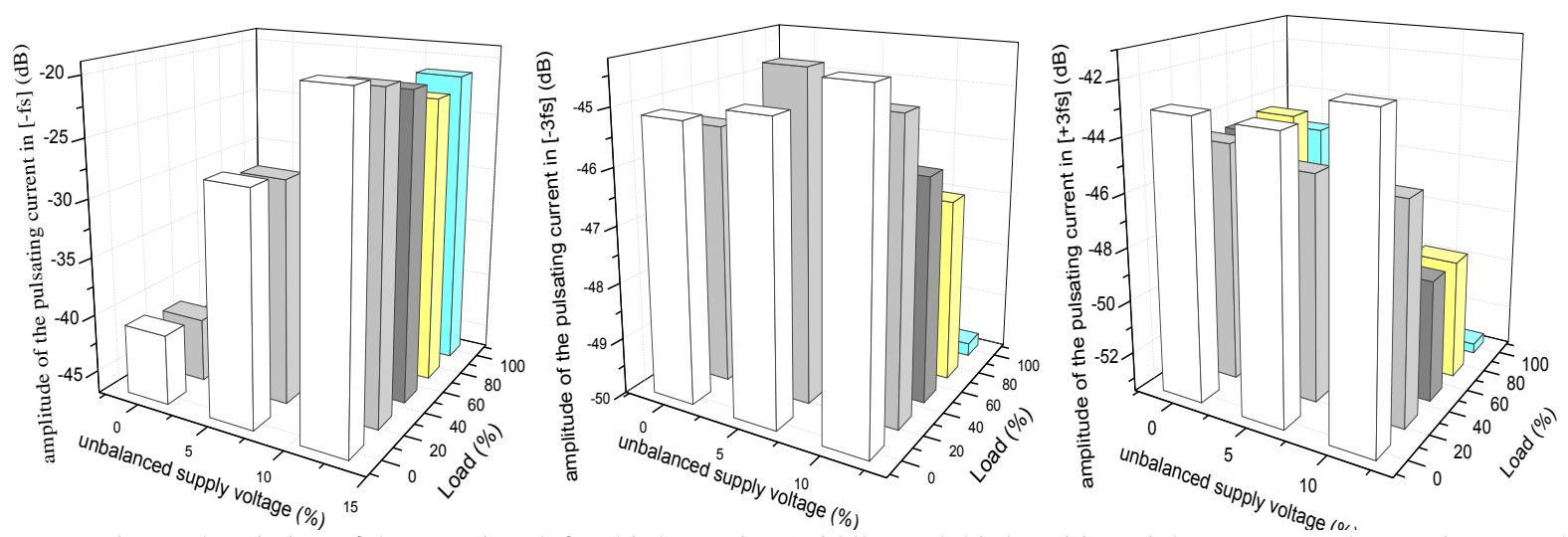

Figure 5. Experimental variation of the negative (left), third negative (middle) and third positive (right) sequences harmonics according to the load percentage under different condition of unbalance supply voltage. 


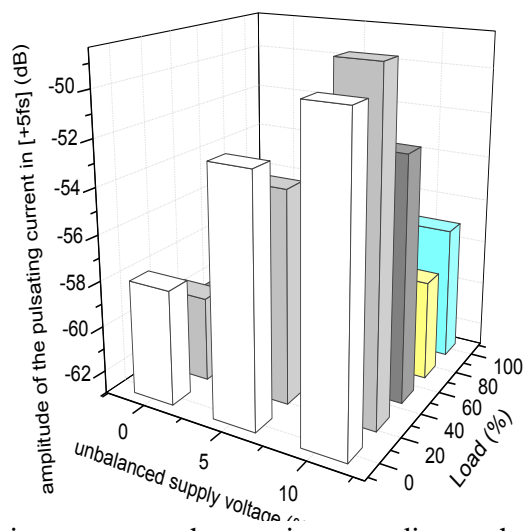

Figure 6. Experimental variation of fifth positive sequences harmonics according to the load percentage under different condition of unbalance supply voltage.

\section{CONCLUSION}

An analytical study of unbalanced supply voltage in induction motors based on the KU transform has been developed in this paper. With this transformation, the dynamics of the machine can be decomposed with a $f-b$ quadrature machine, to describe the behavior of harmonics components in supply voltage due to unbalances. The proposed analytical investigation includes the mathematic development of stator current and speed expressions. An analysis of an example motor has demonstrated the increase in harmonic components amplitude resulting from the voltage unbalance. The analysis also demonstrated that the proposed analytical development of some negative and positive frequencies in stator current spectrum have the same comportment like we show in experimental. Then, we can consider that the analytical development of unbalanced supply voltage conditions is very appreciable and correct.

\section{REFERENCES}

[1] H. Henao, G.-A. Capolino, M. Fernandez-Cabanas, F. Filippetti, C. Bruzzese, E. Strangas, et al., "Trends in fault diagnosis for electrical machines: A review of diagnostic techniques," IEEE industrial electronics magazine, vol. 8, pp. 31-42, 2014.

[2] L. Xiao,H. Sun , F. Gao, S. Hou, L. Li , A New Diagnostic Method for Winding Short-Circuit Fault for SRM Based on Symmetrical Component Analysis. Chinese Journal of Electrical Engineering, Vol.4, No.1, March 2018.

[3] L. Maraaba, Z. Al-Hamouz, and M. Abido, "An Efficient Stator Inter-Turn Fault Diagnosis Tool for Induction Motors," Energies, vol. 11, p. 653, 2018.

[4] H. Abdallah and K. Benatman, "Stator winding inter-turn short circuit detection in induction motors by parameter identification," IET Electric Power Applications, vol. 11, pp. 272-288, 2017.

[5] Andrzej Radecki, Stator winding inter-turn short-circuit modelling of a squirrel-cage induction motor. Power Electronics and Drives. Vol. 1(36), No. 12016.

[6] Sangeeta Sahu, Rudra Narayan Dash, Chinmoy, Kumar Panigrahi, Bidyadhar Subudhi, "Unbalanced Voltage Effects and its Analysis on an Induction Motor", IEEE conf. International Conference on Innovative Mechanisms for Industry Applications (ICIMIA 2017), pp. 263- 268.

[7] Enrique C. Quispe, Ivan D. Lopez, "Effects of Unbalanced Voltages on the Energy Performance of Three-phase Induction Motors ", Conference: Power Electronics and
Power Quality Applications (PEPQA), IEEE Workshop on, At Bogota, Colombia, June 2015.

[8] Qing Wu and Subhasis Nandi, Senior Member, IEEE, "Fast Single-Turn Sensitive Stator Interturn Fault Detection of Induction Machines Based on Positive- and NegativeSequence Third Harmonic Components of Line Currents", IEEE Transactions On Industry Applications, Vol. 46, No. 3, May/June 2010.

[9] Johnny Rengifo, Henryke Salazar, Alexander Bueno and José M. Aller, "Experimental evaluation of the voltage unbalance in the efficiency of induction motors", Conference IEEE Workshop on Power Electronics and Power Quality Applications (PEPQA), At Bogotá, Volume: $3^{\text {rd }}$, May 2017.

[10] Sorin Deleanu, Mihai Iordache, Marilena Stanculescu, Dragos Niculae, "The Induction Machine Operating from a Voltage Supply, Unbalanced and Polluted with Harmonics: A Practical Approach", 15th International Conference on Engineering of Modern Electric Systems (EMES), pp 181$184,2019$.

[11] M. Al-Badri, P. Pillay, P. Angers, “A Novel In Situ Efficiency Estimation Algorithm for Three-Phase Induction Motors Operating with Distorted Unbalance Voltages," IEEE Trans. on Ind. Appl., vol. 53, no.6, pp. 5338- 5347, November/December 2017.

[12] Yaw-Juen Wang, "An Analytical Study on Steady-state Performance of an Induction Motor Connected to Unbalanced Three-phase Voltage ", Conference: Power Engineering Society Winter Meeting, 2000. IEEE, Volume: 1, · February 2000.

[13] Jawad Faiz, Hamid Ebrahimpour, P. Pillay, “ Influence Of Unbalanced Voltage On The Steady-State Performance Of A Three-Phase Squirrel-Cage Induction Motor", IEEE Transactions On Energy Conversion vol.19, no.4, pp 657 662 - January 2005.

[14] Babaa, F. ; Khezzar, A. ; Boucherma, M. ; Nemmour,A.L. "Condition monitoring of stator faults in induction motors: Part I- Analytical investigation on the effect of the negative voltage sequence. " Electrical Machines and Power Electronics, 2007. ACEMP '07. International Aegean Conference on , Pages, 205 - 210, 10-12 Sept. 2007

[15] A. Khezzar, F. Babaa \& M. Boucherma "A steady state analytical study of an unbalanced supply voltage in induction motors: Part II- Analytical investigation of the third harmonic", IEEE International Electric Machines and Drives Conference Antalya, Turkey, May 3-5 2007.

[16] Khezzar A., Davat B., "Active filtering of torque ripples in double stator synchronous machines ", Mathematics and Computers in Simulation, vol. 46, $\mathrm{n}^{\circ}$ : 3-4, 1, mai 1998, $\mathrm{p}$. 349-359, mai 1998. 